\title{
Antenatal corticosteroids and respiratory distress syndrome - the first Polish national survey
}

\author{
Maria Katarzyna Borszewska-Kornacka ${ }^{1}$, Ewa Gulczyńska ${ }^{2}$, Marzena Kostuch ${ }^{3}$, Piotr Korbal' ${ }^{3}$, \\ Paweł Krajewski ${ }^{4}$ and the Polish Study Group \\ ${ }^{1}$ Neonatal Intensive Care Unit, Medical University of Warsaw, Poland \\ ${ }^{2}$ Neonatal Department, Polish Mother's Memorial Hospital Research Institute, Lodz, Poland \\ ${ }^{3}$ Department of Neonatology, Independent Public Clinical Hospital No. 4, Lublin, Poland \\ ${ }^{4}$ Biziel University Hospital No. 2, Bydgoszcz, Poland \\ ${ }^{5}$ Neonatal Department, Pirogow University Hospital of Lodz, Lodz, Poland
}

\begin{abstract}
Objectives: Our retrospective study aimed to evaluate the rate and the appropriate use of antenatal corticosteroid therapy, and their effect on the incidence and treatment of respiratory distress syndrome (RDS) and its complications.

Material and methods: A retrospective analysis of clinical practice in Poland was performed using standard investigating tools: a questionnaire on the frequency of using antennal corticosteroids in the selected centers, as well as neonatal data. A total of 987 newborns at $\leq 32$ weeks of gestation, treated in 54 centers (including 42 tertiary and 12 secondary referral centers) over a period of 6 months in 2013, were deemed eligible. The study group consisted of 749 newborns whose mothers received antenatal steroids. The non-steroid group included 238 newborns.

Results: Antenatal corticosteroids were administered to $75.89 \%$ of the neonates from the study group, with $79 \%$ and $21 \%$ receiving one and two courses, respectively. Children whose mothers received prenatal steroids presented with less extensive radiographic changes typical of RDS, and less often required surfactant therapy (70\% vs. $78 \% ; p=0.0143)$. In the group of children undergoing antenatal steroid therapy, the percentage of BPD was lower ( $13.27 \% \mathrm{vs.} 18.63 \%)(p=0.0881)$ The mortality rates were $20.91 \%$ and $10.81 \%$ in controls and the study group, respectively $(p=0.0001)$.

Conclusions:

1. The percentage of antenatal steroid use in secondary and tertiary referral centers in Poland is unsatisfactorily low (76\%).

2. Antenatal corticosteroids demonstrated high efficacy in decreasing severe forms of RDS, less need for surfactant therapy, and reduced BPD and mortality rates.
\end{abstract}

Key words: antenatal corticosteroids, newborns, RDS, BPD, mortality rate

Ginekologia Polska 2016; 87, 7: 498-503

\section{INTRODUCTION}

Advances in the treatment of preterm neonates have been achieved mainly due to the use of endogenous surfactant and antenatal corticosteroids. Both of these perinatal therapies have significantly decreased the mortality rates among children with low and extremely low birth weight, as well as the number of complications, especially bronchopulmonary dysplasia [1]. The beneficial effect of glucocorticosteroids was discovered over five decades ago. Forty years ago, Liggins, in his study on preterm lambs, observed higher survival rates and less lung damage after administration of these drugs [2]. Experimental studies show a beneficial effect, demonstrated as increased amount of surfactant and respiratory epithelium, resulting in lower permeability and lower leakage of proteins into the alveolar lumens. Glucocorticosteroids accelerate the absorption of lung liquid and maturation of lung interstitium, which in turn has a favorable effect on the total lung capacity [3,4]. Data published in 2000 in Pediatrics, which summed up 20 years of antenatal corticosteroid use, demonstrated their 
safety by reporting no influence on the process of puberty and growth in 12-year-olds who were born preterm and received ACS [5].

\section{OBJECTIVES}

The aim of our study was to evaluate the frequency and the protocol for the use of antenatal corticosteroids in 54 neonatal centers in Poland, including 42 tertiary and 12 secondary referral centers, as well as their effect on the incidence and treatment of respiratory distress syndrome and its complications - bronchopulmonary dysplasia and death.

\section{MATERIAL AND METHODS}

A retrospective analysis of clinical practice in Poland was performed using standard investigating tools: a questionnaire on the frequency of using antennal corticosteroids in the selected centers, as well as data on the incidence of RDS, BPD, and deaths. Data of 987 newborns at the gestational age of $\leq 32$ weeks, treated in 54 centers (including 42 tertiary and 12 secondary referral centers) over a period of 6 months in 2013 (between January 1, 2013 and June 30, 2013), were deemed eligible. The study group consisted of 749 newborns whose mothers received antenatal steroids, whereas 238 of the 987 newborns whose mothers did not receive steroids constituted the control group.

The following parameters were analyzed: the rate of corticosteroid therapy use, severity of RDS, frequency and method of surfactant administration, type of drug, time interval between last dosage and the use of $\mathrm{FiO}_{2}$ during resuscitation in the delivery room, length of invasive ventilation, incidence of BPD (defined as the need to use oxygen therapy at the age of 36 weeks of postconceptional age), as well as the mortality rate. Characteristics of the newborns are presented in Figure 1.

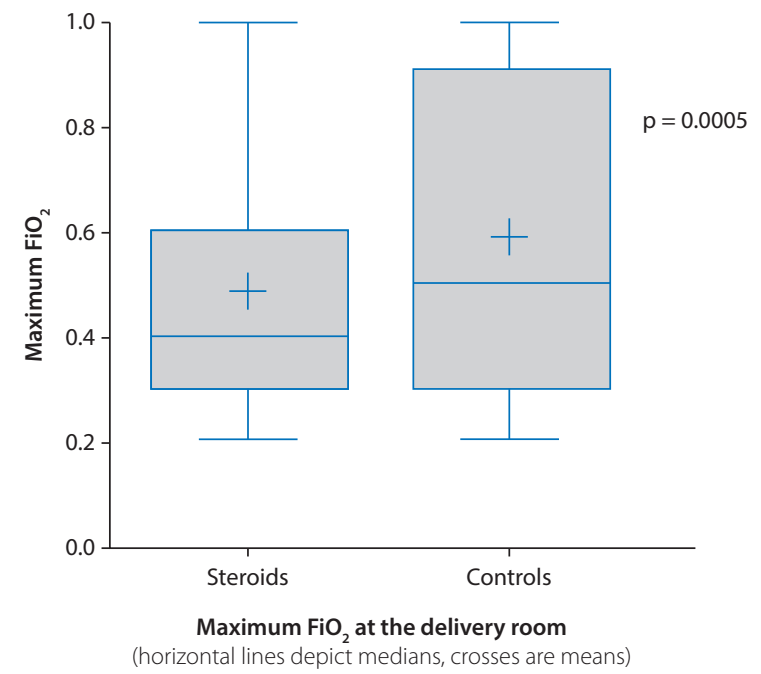

The results of the descriptive analysis of the qualitative data were presented as percentages:

$\mathrm{i}=\mathrm{m} / \mathrm{n} * 100 \%$,

with: $\mathrm{i}$ - coefficient (percentage),

$\mathrm{m}$ - number of subjects with a given feature,

$\mathrm{n}$ - sample size

Each coefficient calculated in the abovementioned way was given a confidence interval.

Quantitative variables were described using measures of central tendency - mean, median (Me) and modal (Mo) values, as well as measures of dispersion and differentiation — standard error (SE), standard deviation (SD), confidence interval $(\mathrm{Cl})$ for the mean, and minimum and maximum value of a variable. The $\mathrm{Cl}$ was established at $95 \%$.

\section{RESULTS}

There were no statistical significant differences in birth weight (mean: $1200 \mathrm{~g}$ ), gestational age (mean: 28 weeks). However, in the study group there were significantly fewer outborn babies $(p<0.0001)$, as well as newborns born with Apgar score $<6$ at 1 min of life (Table 1). Antenatal corticosteroids were administered to $75.89 \%$ of the neonates from the study group, with $79 \%$ and $21 \%$ receiving one and two courses, respectively. The lowest percentage of corticosteroid therapy was noted in mothers of the most premature infants (23-24 weeks of gestational age) and of neonates at 32 weeks of gestational age ( $55 \%$ and $74 \%$, respectively). Table 2 shows the percentage of antenatal steroid administration in different weeks of pregnancy. The time interval between steroid administration and delivery varied, ranging from 0.5 hours to 60 days. Betamethasone and dexamethasone were given to the same number of subjects. We received data on the necessity of intubation in the delivery room about 949 of the 987 newborns. Data were

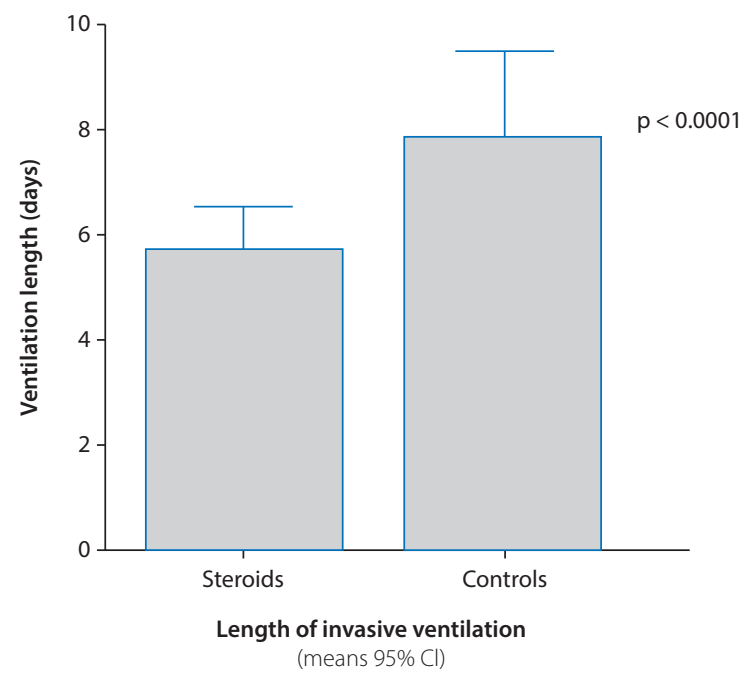

Figure 1. $\mathrm{FiO}_{2}$ at delivery room and length of invasive ventilation in i steroids and control group 
Table 1. Newborns characteristics

\begin{tabular}{|l|c|c|c|}
\hline Characteristics & $\begin{array}{c}\text { Antenatal corticosteroids } \\
(\mathbf{n = 7 4 9 )}\end{array}$ & $\begin{array}{c}\text { Controls } \\
(\mathbf{n = 2 3 8 )}\end{array}$ & P value \\
\hline Birth weight, 9 , mean $\left(5^{\text {th }}, 95^{\text {th }}\right.$ percentile) & $1216(600,1980)$ & $1209(520,2021)$ & 0,6465 \\
\hline $\mathrm{GA}$, wk, mean $\left(5^{\text {th }}, 95^{\text {th }}\right.$ percentile) & $28.7(24,32)$ & $28.3(23,32)$ & 0.3191 \\
\hline Sex, male, $\mathrm{n}[\%]$ & $390(52.0)$ & $124(52,1)$ & 0.9933 \\
\hline Outborn, $\mathrm{n}[\%]$ & $38(5.0)$ & $54(22,7)$ & $<0.0001$ \\
\hline Apgar at 1 min, median (IQR) & $6(4-7)$ & $5(2-6)$ & $<0.0001$ \\
\hline Apgar at 5 min, median (IQR) & $7(6-8)$ & $7(6-8)$ & 0.0084 \\
\hline Maximal FiO ${ }_{2}$ at DR, mean $\left(5^{\text {th }}, 95^{\text {th }}\right.$ percentile) & $0.49(0.25,1)$ & $0.59(0.29,1)$ & 0.0005 \\
\hline Surfactant treatment, $n[\%]$ & $524(69.9)$ & $186(78.1)$ & 0.0143 \\
\hline
\end{tabular}

Table 2. Antenatal steroids in different weeks of pregnancy in study and control group

\begin{tabular}{|c|c|c|}
\hline $\begin{array}{c}\text { Gestational age } \\
\text { [weeks] }\end{array}$ & $\begin{array}{c}\text { Steroids group } \\
{[\%]}\end{array}$ & $\begin{array}{c}\text { No steroids group } \\
{[\%]}\end{array}$ \\
\hline 22 & 33.33 & 66.67 \\
\hline 23 & 55.00 & 45.00 \\
\hline 24 & 63.46 & 36.54 \\
\hline 25 & 82.00 & 18.00 \\
\hline 26 & 78.35 & 21.65 \\
\hline 27 & 74.44 & 25.56 \\
\hline 28 & 80.18 & 19.82 \\
\hline 29 & 81.25 & 18.75 \\
\hline 30 & 74.50 & 25.50 \\
\hline 31 & 78.03 & 21.97 \\
\hline 32 & 73.68 & 26.32 \\
\hline
\end{tabular}

analyzed in four groups, depending on the time elapsed since the last dose of steroids until birth:

1. the last dose was given between $24 \mathrm{~h}$ ( $=1$ day) to 14 days before delivery;

2. no steroids were administered prenatally;

3. the last dose was given at a different time than 1-14 days before delivery;

4. steroids were given but time of the administration is unknown (Table 3).
In 719 newborns maximal $\mathrm{FiO}_{2}$ at the Delivery Room (max$\mathrm{FiO}_{2}$ ) was noted. Mean values of $\mathrm{maxFiO}_{2}$ were 0.59 and 0.49 in the control and the study group, respectively $(p=0.0005)$ (Figure 1). We obtained data on mechanical ventilation about all 987 newborns. Mean time of invasive ventilation was 7.8 days and 5.7 days, respectively in the non-steroid and steroid groups $(p<0.0001)$ (Figure 1). Children whose mothers received prenatal steroids presented less extensive radiographic changes typical of RDS and less often required surfactant therapy (70\% vs. 78\%; $p=0.0143$ ) (Table 1, Figure 2). As many as $93.1 \%$ of the newborns (gestational age of $<28$ weeks) whose mothers did not receive antenatal corticosteroids required surfactant therapy. The incidence of BPD was analyzed in 726 newborns. In the group of children undergoing antenatal steroid therapy, the percentage of BPD was lower (13.27\% vs. 18.63\%) $p=0.0881 \mathrm{RR}=0.7124$ (Figure 2 ). The mortality rate was $20.91 \%$ in the control group and $10.81 \%$ in the study group $(p=0.00001) R R=0.5172$ (Figure 2 ). These data are statistically significant.

In summary, in children who received prenatal corticosteroids, as compared to infants not exposed to corticosteroids, the following were observed:

1. lower risk of death within a period of 36 weeks of postconceptional age $(10.8 \%$ vs. $20.9 \%$ in control $\mathrm{p}=0.0001 ; \mathrm{RR}=0.5172$ [95\% Cl: 0.3695-0.7239]);

2. lower risk of the need for surfactant treatment (respectively, $69.9 \%$ vs. $78.1 \%$ in control $p=0.0143$; $\mathrm{RR}=0.8952[95 \% \mathrm{Cl}: 0.8247-0.9716]) ;$

Table 3. Intubation at delivery room and antenatal steroids

\begin{tabular}{|l|c|c|c|c|c|c|}
\hline INTUBATION & $\begin{array}{c}\text { Steroids } \\
\mathbf{1 - 1 4} \text { days before delivery }\end{array}$ & No steroids & $\begin{array}{c}\text { Steroids } \\
\text { > 14 days before delivery }\end{array}$ & $\begin{array}{c}\text { Steroids } \\
\text { Unknown time before delivery }\end{array}$ & Total number \\
\hline NO & $\mathrm{N}-255$ & $\mathrm{~N}-121$ & $\mathrm{~N}-145$ & $\mathrm{~N}-18$ & 542 \\
\hline & $59.72 \%$ & $51.95 \%$ & $60.41 \%$ & 40.91 & 407 \\
\hline YES & 172 & 112 & 97 & 26 & $59.09 \%$ & 949 \\
\hline
\end{tabular}




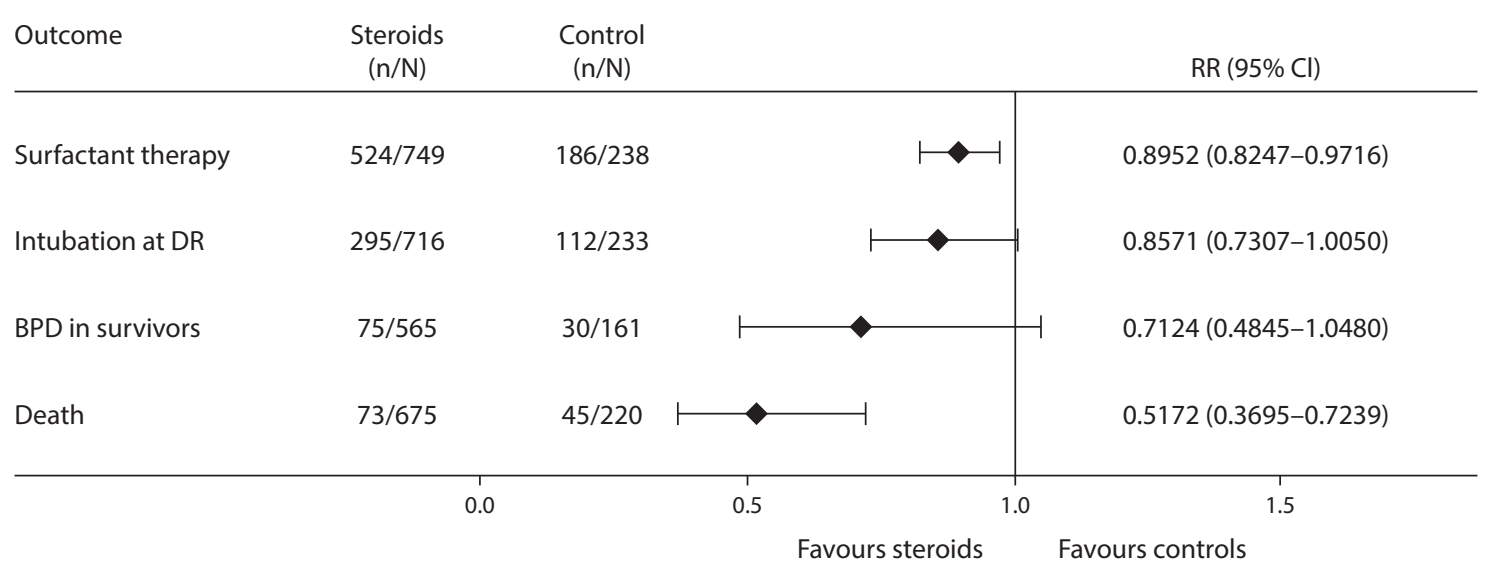

Figure 2. Relative Risk of incidence of intubation at delivery room, surfactant therapy, BPD and death in study and control group

3. lower oxygen demand - lower max. value $\mathrm{FiO}_{2}$ during stabilization in the delivery room (median $\mathrm{FiO}_{2}$ of 0.4 and 0.5 , respectively, $\mathrm{p}=0.0005$, the U Mann-Whitney test);

4. less invasive ventilation time (average $5.7 \pm 1.4$ days and $7.9 \pm 12.7$ days, respectively; $p<0.0001$ );

5. a trend for less frequent need for intubation immediately in the delivery room in the group of children whose mothers received the last dose of steroids in the period of $>24 \mathrm{~h}$ and $<14$ days before giving birth, as compared to children who did not receive steroids ( $40.3 \%$ vs. $48.0 \%, p=0.0535)$. A statistically significant difference was observed between the use of prenatal steroids depending on gestational age $(p=0.00836)$; the least frequent use at 22 and 23 weeks (33.33\% and $55 \%$ of the children).

\section{DISCUSSION}

Despite over 19000 articles on antenatal corticosteroid therapy to be found in PubMed, as well as the fact that antenatal steroids and surfactant have been used for forty years, Poland lacks satisfactory amount of data on mutual correlations of these drugs. Our findings regarding almost 987 newborns aimed to bridge that gap. The National Institutes of Health (NIH), the American College of Obstetricians and Gynecologists (ACOG), and other associations also Polish Gynecological Society have been recommending administration of antenatal corticosteroids before 34 weeks of gestation in women at risk for preterm birth since the end of the twentieth century $[6,7]$. The latest reports have recommended steroid use until 36 weeks of gestation, as such management decreases morbidity and mortality rates of most preterm neonates Detailed reports on the rules governing ACS use were included in four recommendations of the Royal College of Obstetricians and Gynecologists, published in 1996, 1999, 2004 and 2010 [8-11]. In 2008, the guidelines of the World Association of Perinatal Medicine Prematurity Working Group on the use of ACS to stimulate fetal lung maturity were published in the Journal of Perinatal Medicine [12]. Numerous other reports summarize large amount of data documenting the effect of these drugs on the stimulation of type II pneumocytes and release of surfactant, and the efficacy and necessity of their use, which surpasses the possible adverse effects $[13,14]$. A meta-analysis of data collected by Crowley, from 15 projects published over a period of 22 years (1972-1994), revealed a $50 \%$ drop in the RDS rates (OR 0.35; 95\% Cl: 026-0.46), as well as lower rates of intraventricular hemorrhage - IVH (OR 0.38; 95\% Cl: 0.23-0.94) and necrotizing enterocolitis — NEC (OR 0.32; 95\% Cl: 0.16-0.64), but did not show any correlation between corticosteroid use and the incidence of BPD [15]. Similar findings were reported by Spencer and Neales, who observed decreased rates of IVH and NEC, as well as a group of neonatologists from Brazil, who studied 1051 neonates born < 34 weeks of gestation $[16,17]$. Our study was limited only to the evaluation of clinical severity of RDS, as well as intubation in the delivery room, mechanical ventilation BPD rates of death. We demonstrated lower RDS rates, and a less frequent need for surfactant use in the study group as compared to children whose mothers did not receive steroid therapy (70\% vs. 78\%) (Figure 2). Neonates who received corticosteroids in utero notably less often required surfactant therapy or developed BPD. The $75.89 \%$ rate of administration of antenatal steroids noted in our study remains too low. The percentage of using ACS in other European countries is much higher (95\%), whereas in Australia it reached the level of $97 \%$ already in the 90 s of the previous century [18]. However, an analysis of 9 Scottish centers detected a 45\% ACS use [19]. Currently, 210 centers in Great Britain declare a $98 \%$ rate of ACS use [20]. The low rate of administering ACS to Polish neonates at the gestational age of 22-23 weeks, i.e. (33.3\% and 55\%), when 
neonatologists often choose not to intervene and limit their activity to palliative care, may be interpreted in various ways. On one hand, it indicates that obstetricians are convinced, sometimes mistakenly, of low chances to maintain pregnancy in the face of such early threat of premature labor, and on the other hand, of lack of a favorable effect of ACS on immature lungs. The rationale behind such opinions is the fact that glucocorticoid activity is conditioned by the number of receptors for corticosteroids, physiological activity of hormones, and genetic factors [3]. Typically, one course of steroids is administered in daily obstetric practice, whereas the second course continues to remain controversial if preterm labor did not occur in a few weeks after the first course. In our study, one course of ACS $-2 \times 12 \mathrm{mg}$ at $24 \mathrm{~h}$ intervals - was also the dominant management $(79 \%$ and $21 \%$ ). Already by the end of the previous century, most American and European obstetrician used more than one course of ACS. However, despite reports on higher efficacy of repeated ACS courses on the parameters of lung function, especially in neonates with significant immaturity, such management was largely abandoned due to growth restriction, decreased brain volume, and unclear long-term effects [21]. After numerous experimental and randomized studies, in 2005 the National Institute of Health of the U.S. Health Department published a statement declaring the lack of scientific rationale for validity and efficacy of repeated courses of steroid therapy [22]. These recommendations were confirmed, among others, by experimental studies on monkeys, sheep, rabbits, and mice, indicating delayed brain development and growth retardation, as well as increased rates of NEC and sepsis [23]. In our study, the time elapsed between the last dose of corticosteroids and the delivery varied greatly. As many as $25 \%$ of the subjects gave birth $<24 \mathrm{~h}$ since the administration of the drug. The actual efficacy is perhaps extremely low, but most recommendations claim a beneficial effect of the therapy even in such cases. Already Liggins and Howie, in their practically 'historical' publication from 1972, proved the highest efficacy of steroid therapy after $24 \mathrm{~h}$ of life until up to 10 days since its commencement [2]. Our data indicate an equal frequency of betamethasone and dexamethasone use but, obviously, their dosing schemes differ, and Polish hospitals do not always comply with them. Betamethasone is given as two doses of $12 \mathrm{mg}, 24 \mathrm{~h}$ apart, and dexamethasone as four doses of $6 \mathrm{mg}, 12 \mathrm{~h}$ apart [24]. Both drugs are recommended by experts worldwide. Although the only structural difference between both drugs is one methyl group, and despite having different transfer across the placenta, in cord blood they both reach approximately $30 \%$ of drug activity in maternal blood and both have immunosuppressant activity, as well as minimal activity of mineralocorticoids. Nevertheless, Job and Soll emphasize a higher efficacy of betametha- sone in reducing mortality rates among neonates, possibly caused by its longer half-life and lower concentrations in blood serum [25]. Other studies demonstrate a decreased risk for leukomalacia after betamethasone treatment [26].

\section{CONCLUSIONS}

1. The percentage of glucocorticosteroids used in secondary and tertiary referral centers in Poland is unsatisfactorily low (76\%), and differs from other European, American, or Australian centers.

2. The protocols for the use of ACS and the doses are consistent with European and global recommendations.

3. Based on a large sample size of 987 neonates at the gestational age of $\leq 32$ weeks from 54 Polish neonatal centers, we demonstrated high efficacy of antenatal corticosteroid use in decreasing severe forms of RDS, lower necessity of surfactant therapy, and reduced BPD and mortality rates.

\section{Source of financing}

Financial support for this study was provided by Chiesi Poland Sp. z o.o.

\section{REFERENCES}

1. Konefał H, Czeszyńska MB, Merritt TA. School-age spirometry in survivors of chronic lung disease of prematurity in the surfactant era. Ginekol Pol. 2013, 84 (4), 286-292.

2. Liggins GC, Howie RN. A controlled trial of antepartum glucocorticoid treatment for prevention of the respiratory distress syndrome in premature infants. Pediatrics. 1972, 50, 515-519.

3. Ballard PL. Scientific Rationale for the Use of Antenatal Glucocorticoids to Promote Fetal Development. NeoReview. 2000, 1 (5), e83-e90.

4. Roberts D, Dalziel S. Antenatal corticosteroids for accelerating fetal lung maturation for women at risk of preterm birth. Cochrane Database Syst Rev. 2006, 19 (3), CD004454.

5. Dessens AB, Haas HS, Koppe JG. Twenty-year follow-up of antenatal corticosteroid treatment. Pediatrics. 2000, 105 (6), E77-E81.

6. ACOG Committee on Obstetric Practice. ACOG Committee Opinion No. 475: Antenatal corticosteroid therapy for fetal maturation. Obstet Gynecol. 2011, 117, 422-424.

7. Rekomendacje zespołu ekspertów Polskiego Towarzystwa Ginekologicznego dotyczące opieki okołoporodowej i prowadzenia porodu. Ginekol Pol. 2009, 80 (7), 548-557

8. ACOG Committee on Practice Bulletins - Obstetrics. ACOG practice bulletin no. 127: Management of preterm labor. Obstet Gynecol. 2012, 119 (6), 1308.

9. RCOG Guidelines. Number 7. ACS to prevent respiratory distress syndrome. RCOG, London 1996.

10. RCOG Guideline. No. 7. Antenatal corticosteroids to prevent respiratory distress syndrome. London 2004.

11. RCOG Green-Top Guideline No. 7 Antenatal Corticosteroids to Reduce Neonatal Morbidity and Mortality. London 2010.

12. Miracle X, Di Renzo GC, Stark A, [et al.]. Guideline for use of antenatal corticosteroids for fetal maturation. J Perinat Med. 2008, 36 (3), 191-196

13. Roberts D, Dalziel $S$. Antenatal corticosteroids for accelerating fetal lung maturation for women at risk of preterm birth. Cochrane Database Syst Rev. 2006, 19 (3), CD004454.

14. Report on the Consensus Development Conference on the Effect of Corticosteroids for Fetal Maturation on Perinatal Outcomes. U.S. Department of Health and Human Services, Public Health Service, NIH Pub No. 95-3784. November 1994

15. Crowley P, Chalmers I, Kierse MJ. The effects of corticosteroid administration before preterm delivery: an overview of the evidence from controlled trials. Br J Obstet Gynaecol. 1990, 97 (1), 11-25. 
16. Spencer $C$, Neales K. Antenatal corticosteroids to prevent neonatal respiratory distress syndrome. BMJ. 2000, 320 (7231), 325-326

17. Meneguel JF, Guinsburg $\mathrm{R}$, Miyoshi MH, [et al.]. Antenatal treatment with corticosteroids for preterm neonates: impact on the incidence of respiratory distress syndrome and intra- hospital mortality. Sao Paulo Med J. 2003, 121 (2), 45-52.

18. Quinlivan JA, Evans SF, Dunlop SA, Beazley LD, Newnham JP. Use of corticosteroids by Australian obstetricians - a survey of clinical practice. Aus NZ J Obstet Gynaecol. 1998, 38 (1), 1-7.

19. Scottish Neonatal Consultants's Collaborative Study Group; International Neonatal Network. Trends and variations in use of antenatal corticosteroids to prevent neonatal respiratory distress syndrome recommendation for national and international comparative audit. Br J Obstet Gynaecol. 1996,103 (6), 534-540.

20. Brocklehurst $P$, Gates $S, M c K e n z i e-M c H a r g ~ K$, [et al.]. Are we prescribing multiple courses of antenatal corticosteroids? A survey of practice in UK. Br J Obstet Gynaeco. 1999, 106 (9), 977-979.
21. Bonano C, Fuchs K, Wapner RJ. Single versus repeat courses of antenatal steroids to improve neonatal outcome: risks or benefits. Obstet Gynecol Surv. 2007, 62 (4), 261-271

22. National Institute of Health Consensus Development Panel. Antenatal corticosteroids revisited: repeat courses. National Institute of Helath Consensus Development Conference Statement, August 17-18, 2000. Obstet Gynecol. 2001, 98 (1), 144-150.

23. Aghajafari F, Murphy K, Matthews S, [et al.]. Repeated doses of antenatal corticosteroids in animals: a systematic review. Am J Obstet Gynecol. 2002, 186 (4), 843-849.

24. Merill JD, Ballard RA. Clinical use of antenatal corticosteroids: benefits or risks. NeoReviews. 2000, 1 (5), e91-e98.

25. Jobe AH, Soll RF. Choice and dose of corticosteroid for antenatal treatments. Am J Obstet Gynecol. 2004, 190 (4), 878-881.

26. Lee BH, Stoll BJ, McDonald SA, [et al.]. Adverse neonatal outcomes associated with antenatal dexamethasone versus antenatal betamethasone. Pediatrics. 2006, 117 (5), 1503-1510.

\section{Polish Study Group}

Biała Podlaska: Riad Hajdar, Białystok: Marek Szczepański, Bielsko-Biała: Jolanta Kublin-Korzonkiewicz, Bydgoszcz: Piotr Korbal, Iwona Sadowska-Krawczenko, Bytom: Katarzyna Szczepańska, Częstochowa: Jolanta Warzycha, Grzegorz Zieliński, Elblag:Wawrzyniec Pruszak, Gdańsk:Wojciech Gargula, Agata Krzysztofowicz, Agata Polkowska, Gorzów Wlkp.: Małgorzata Dzięgielewska, Marzena Gendera-Dudziak, Jastrzębie Zdrój: Józef Danek, Kalisz: Magdalena Siuda-Całus, Katowice: Małgorzata Fiala, Kielce: Grażyna Pazera, Konin: Anna Walbach-Gołębiowska, Kraków: Agata Bocheńska, Paweł Lauterbach, Marta Orczyk, Anna Piątkowska, Elżbieta Rafińska-Ważny, Beata Rzepecka-Węglarz, Lublin: Elżbieta Szmit, Lublin: Marzena Kostuch, Łódź: Alicja Adamek, Anita Chudzik, Beata Jędrzejewska, Marcin Kęsiak, Nowa Sól: Karolina Płomińska, Nowy Targ: Mirosława Frankowska-Majchrzak, Olsztyn: Jolanta Meller, Opole: Dominika Chrzanowska-Grzywacz, Ostrów WIkp.: Katarzyna Bierła, Płock: Elzbieta Rudowska, Joanna Tim-Kanar, Police: Brygida Jaskot, Poznań: Anna Jaworska, Radom: Alicja Powoniak, Anna Ściszek Rzeszów: Elżbieta Cioch, Małgorzata Stefańska, Szczecin: Agnieszka Kordek, Jacek Patalan, Tarnów: Wiesław Olechowski, Toruń: Hanna Dąbrowska, Małgorzata Górczyńska, Wałbrzych: Małgorzata Klemke, Warszawa: Maria K. Kornacka, Maria Kostro, Joanna Kozłowska, Magdalena Kurzątkowska, Hanna Michałek-Baranowska, Olga Pawlik, Marzanna Reśko-Zachara, Magdalena Rutkowska, Anna Wilanowicz-Sałek, Jacek M. Witwicki, Joanna Żytyńska-Daniluk, Wrocław: Kamila Dudziak, Tomasz Janusz, Agata Pająk, Zabrze: Jakub Behrendt, Anna Szymańska 